\title{
Abstracts
}

\section{Sociology and Ageing}

\section{Tim Dant}

Bill Bytheway, Ageing and biography: The letters of Bernard and Mary Berenson, Sociology, 27, 1 (1993), 153-165.

This article is one of fifteen published as a special issue of the journal of the British Sociological Association, Sociology, on the topic of 'Auto/biography in sociology'. Bytheway is not only contributing to a recently rediscovered interest in biography amongst sociologists, particularly feminist social researchers, but situates his piece within a gerontological tradition concerned with documenting ageing in terms of the life course and personal biography to which he has contributed over a number of years.

His aim in this paper is to show that people theorise ageing as they construct and reconstruct their biography through their own life course. He adopts the concept of 'ordinary theorising' set out in a provocative article by Gubrium and Wallace (1990). Ordinary theorising is the theoretical work undertaken by people who do not claim a special theoretical competence. The basis for such ordinary theorising is not systematic examination but actual experience. Letters are used as a source for biography because they provide a series of utterances, located in time and place, that may among other things refer to the current experience of the author, including their experience of ageing. They are not then conscious life review work undertaken at the later stage of life but the at-the-time reflections of someone experiencing the process of ageing. They are of course exchanges between writer and intended reader of the letter, a moment in a flow of correspondence, but they also have what Bytheway calls a 'oneperson statement quality' in which the writer may take the:

opportunity to articulate narrative on theory, free from interruption, but with possibility of some form of future reaction, either from the self or from another, the recipient (p. 155).

Bytheway extracts the theorising from the published letters of a married couple, Bernard and Mary Berenson, who were closely involved in the world of art in the first half of this century. A small proportion of their 
letters have been published in two edited volumes which provide Bytheway with his source material. He extracts small pieces for their relevance to the topic of ageing. From these extracts he reconstructs a life-course view of ageing for each of these two people; for Mary there are comments on childhood, youth, middle age and old age. For Bernard, ageing seems to start with middle age (the first reflection that Bytheway quotes refers to his fixity of character at age 42 years) and progresses to late old age (twelve of the eighteen extracts quoted refer to his life beyond the age of eighty).

From the extracts Bytheway constructs fourteen theoretical categories dealing with ageing that are utilised by either or both Mary and Bernard. None are surprising: development, no change, routine, a series of stages, decline and loss, adversity, a process of contingency, humiliation, scheduled change, accelerated change, distance from other people, the (un)productive use of time and finitude. Bytheway claims that these categories are common to both of his letter writers but that the way that they are used is gendered. This is connected, he suggests, with Bernard's concern with 'his work' in contrast to Mary's involvement with her family. However, he tells us that Bernard had no family while Mary had two children from a previous marriage. He notes that Bernard figured prominently in Mary's letters while references to her in his correspondence only began to appear when her illness threatened his programme of work.

While the overall thrust of Bytheway's paper is to explore the theoretical categories used by these letter writers to express their experience of ageing, he points out that the editors of the two source volumes have constructed biographies of these two people by their selection of material. Nonetheless Bytheway is clear about what can be understood from the theorising of these two letter writers:

This process of theorising has led to a clear contrast between male and female accounts. Although qualified by their different levels of health and longevity, Mary offers an account of ageing that is dominated by reverence for youth, the drama of domestic conflict and a growing devaluation of her abilities as she ages. In contrast, for most of his adult life Bernard largely ignores age, at most denying it to be of any consequence. As his capacity for work declines, he begins to 'celebrate' his age largely through its numerical size but, through theories relating to time, energy and finitude, he regretfully abandons his continuing ambition. (p. 164 ).

COMMENT

These are powerful conclusions and we must assume that Bytheway has much more evidence to support them than he has presented or alluded 
to. The picture of male and female ageing that emerges is a classic differentiation along the family/work dichotomy by which much gendered experience is distinguished. However, while Bernard is in nine of the extracts concerned with work, in only one extract from Mary is she doing anything like engaging with domestic dramawriting to her daughter. Mary does reflect on herself and in three extracts compares her ageing self with younger selves - but then Bernard similarly reflects on his ageing self and its failing capacities. It would have been helpful if the discussion had made the theoretical status of the fourteen categories clearer, and particularly had differentiated the participants' theoretical categories and the interpreter's theorising. Insofar as they are categories used by participants to make sense of their experience, they do not necessarily constitute theory in the gerontologist's or sociologist's sense. There is for example no attempt at conceptual clarity or general applicability since these are not requirements of 'ordinary theorising'. And of course the task of arranging concepts into a list according to a topic such as ageing is characteristic of social theory but unnecessary for letter writing. I hope Bytheway takes a more leisurely opportunity to explore some of these issues as well as expanding on the presentation of source material.

\title{
Reference
}

Gubrium, J. and Wallace, B. 1990. Who theorises age? Ageing and Society 10, 2, 131-50.

\begin{abstract}
Powers, Edward A. and Kivett, Vira R., Kin expectations and kin support among rural older adults, Rural Sociology, 57, 2 (1992), $194^{-2} 15$.
\end{abstract}

This article reports a survey to gather information on the kin linkages of older rural adults and the factors associated with the assistance that kin network members provide. It builds on previous research which shows that elderly people in rural areas are more likely than their urban counterparts to have lower incomes, experience greater health problems, be more dependent on private cars and live in less adequate housing. At the same time the formal support services and appropriate health care in rural environments are less accessible and more costly to deliver. The survey used a compact multi-stage area cluster technique to construct a sample of 368 . The technique allowed enumeration districts to be randomly selected within specified zones and then 
intensively surveyed. The sample drawn was stratified for race with approximately $52 \%$ of the final sample being white. The response rate was $82 \% .64 \%$ of the respondents were women. The mean age was 75 years and $74 \%$ had been either blue collar workers or farmers. The research used Bengtson's theory of intergenerational solidarity as a conceptual basis. As well as considering the helping behaviour of kin, this approach led the researchers to consider the sense of kin obligation, including expectations of support and the degree of consensus among family members.

The findings were that elderly people living in rural areas had reasonably high expectations of assistance from children if help was needed. They had more moderate but similar expectations of childrenin-law, grandchildren and siblings. They expected lower levels of help from secondary kin (sib-in-laws, niece/nephews, cousins). Approximately three-quarters of the older respondents felt that children should regularly visit an older parent and provide help if a parent were sick. Three-fifths felt children should provide a home for a parent, provide services such as transportation and assist financially if a parent needed it. They felt that other members of the family of children and siblings (children-in-law, grandchild, siblings) should provide these forms of support to a slightly lesser degree. More distant relations (secondary kin) had even less expected of them; only a few respondents thought they should provide a home, but about two-fifths expected visiting and helping of these relations when sick. The overall level of assistance was low for all categories of kin and varied according to familial distance. This was of course a group of elderly people who were largely well (only one in nine was confined to a bed or chair or had difficulty getting around the house). Between a quarter and a third of respondents were receiving help from their children with transport, housekeeping, shopping, help with a parent who was ill or decision making. Other members of the kin system seldom gave regular assistance although about a tenth of secondary kin did provide help when the elderly person was ill.

The researchers used a hierarchical regression technique to model the factors that led to support. More assistance was achieved from children when the parents were older black, female, in good health, and widowed. However, only one characteristic of the children was related to the help older parents received - geographical proximity. Two factors predicted the amount of assistance received; high expectations and high consensus. In all other kin relationships proximity was the dominant factor in predicting the amount of support received. Not surprisingly, relatively high levels of support were 
received if the kin shared the household with the older people. However, the researchers found that the amount of assistance provided by many of the kin was not significantly different regardless of where outside the household they lived.

A key contribution of this piece of research claimed by the authors is that caregiving by kin follows a 'modified kin selection principle' i.e. that kin are expected to and in fact do provide assistance along a sequence of kin proximity that runs: child, child-in-law, grandchild, sibling, sib-in-law, niece/nephew, cousin. For most purposes this sequence can be abbreviated to: child, other primary kin, secondary kin. On the general conclusion that the gender of the caregiver was not important for the level of help that children and their families provided older adults, this was clearly a result of the type of help being discussed; it did not focus on personal care tasks for frail elderly people but included a range of tasks often provided for well elderly people.

\section{GOMMENT}

This paper supports other surveys that are building an overall picture of the kin support for elderly people in rural settings. It also uses its empirical findings to contribute to the theoretical debate about the relative significance of kin proximity and geographical proximity in determining levels of support. As such it is not path-breaking or likely to be of interest to someone not already engaged with this topic. I found the survey method and analytical techniques to be limited in their references to theoretical concepts. For example, 'obligation' is a confusing word to use when it is the elder person's sense of someone else's obligation that is being discussed; the kin were not interviewed and their sense of their own obligation is not actually considered. It is never explained how the concept of 'consensus' was dealt with in the survey. The data in the paper are always presented in terms of percentages which makes it difficult to be sure exactly what numbers were included in categories or sub-categories. However, since the paper offers neither surprising nor contentious results, it is easy to accept its style.

Department of Sociology,

Metropolitan University of Manchester, Manchester 